\title{
PALAVRAS NÃO SÃO DE NINGUÉM: As múltiplas vozes que ecoam na produção escrita em sala de aula
}

José Adailton Cortez Freire Nadja Naira Aguiar Ribeiro ${ }^{(*)}$

\section{INTRODUÇÃO}

Refletir sobre a escrita na perspectiva da produção textual é, na verdade, caminhar por uma espécie de labirinto da linguagem. Cercada de meandros, percebe-se que a escrita, enquanto atividade linguística é, por excelência, social, interativa e dialógica. Escrever é encontrar-se, é (re)velar-se, é movimentar-se a todo instante na direção do outro. "O outro é a medida: é para o outro que se produz o texto. E o outro não se inscreve no texto apenas no seu processo de produção de sentidos na leitura. O outro insere-se já na produção, como condição necessária para que o texto exista" (GERALDI, 2003, p. 102). A partir desse movimento, dessa noção de alteridade, é que o sujeito - histórico e ideológico - se desfaz e se refaz na tessitura do texto. O ato de escrever, sobretudo, configura-se como uma atividade sociointerativa e dialógica. A partir dessa perspectiva bakhtiniana e, em diálogo com estudiosos da linguagem, como Geraldi (2003) e Faracco (2009), surgiu esse trabalho.

Diante disso, compreende-se que a produção textual na escola não é importante apenas para o sucesso escolar, mas sobremaneira para que o indivíduo tenha condições de utilizar o conhecimento da e pela escrita de modo a emancipar-se, interagindo no meio em que vive e modificando-o sempre que necessário.

Assim, esse artigo procura compreender os indícios linguísticos na composição escrita (redação de vestibular) dos alunos do $3^{\circ}$ Ano do Ensino Médio, destacando possibilidades de atravessamento das mais variadas vozes que, a cada instante, circulam em sala de aula ou mesmo fora dela.

\footnotetext{
${ }^{(*)}$ JOSÉ ADAILTON CORTEZ FREIRE. Mestre em Educação pela Universidade Federal de Alagoas (UFAL)(2014), na linha de pesquisa Educação e Linguagem (CEDU/PPGE/UFAL). Graduado em Comunicação Social - Jornalismo (UFAL)(2010) e em Letras - Português pelo Instituto Federal de Alagoas (IFAL)(2013). E-mail: dal.freire@hotmail.com.

Nadja Naira Aguiar Ribeiro. Professora Associada da Universidade Federal de Alagoas (UFAL), lotada no Centro de Educação (CEDU). Pós-doutora em Educação pelo Proped/UERJ. E-mail: nnaquiar@hotmail.com.
} 
A coleta de dados se deu numa escola da rede pública estadual ${ }^{1}$, no turno da noite, e contou com a participação de 29 alunos na faixa etária entre 18 e 39. Por questões éticas, a escola recebeu o nome fictício de "Guimarães Passos" em homenagem a um célebre poeta alagoano, imortalizado ao assumir a cadeira de número 26 da Academia Brasileira de Letras (ABL).

É também pertinente destacar que apesar de o texto escrito dos alunos compor o corpus da pesquisa, a ideia foi não se deter em aspectos gramaticais e/ou normativos, mas compreender especialmente o mo(vi)mento do texto, dentro do ambiente escolar, considerando um conjunto de vozes que ecoam em sala de aula, seja a do professor, a dos textos motivadores, a dos demais alunos ou do mundo em volta.

\section{O JOGO DAS ESCOLHAS: O LUGAR E A POSIÇÃO DE PESQUISADOR}

Outro aspecto que se constitui relevante, do ponto de vista metodológico, e, por tal razão, merece ser posta em relevo é o fato de o próprio pesquisador também constituir-se sujeito da pesquisa, uma vez que é ele o professor/ monitor $^{2}$ da disciplina de Língua Portuguesa nas turmas de $3^{o}$ ano - do Ensino Médio noturno, nessa escola Guimarães Passos - lócus da investigação. A decisão de assumir tal empreendimento não deixou de ser um desafio, pois essa implicação obrigou, de alguma forma, estar às voltas com o "meu” problema. Ao se colocar ao mesmo tempo no lugar de pesquisador da própria prática, não se pode mais olvidar dos procedimentos didáticometodológicos praticados em sala de aula que não deixam de estar implicados com as diferentes (indis)posições que afetam os sujeitos na escrita de suas redações.

Pesquisar a própria prática é aceder a um "excedente de visão" - numa espécie de "visão exotópica" (BAKHTIN, 2003), ${ }^{3}$ permitindo-se ao jogo da alteridade consigo mesmo - na perspectiva do Outro. Esse Outro se revela em enunciados outros, desalojado de uma dimensão puramente individual - numa contemplação estética do seu fazer pedagógico. Ou seja, “[...] tornar-

\footnotetext{
${ }^{1}$ A escola pública está localizada no município de Boca da Mata, a 72km de Maceió, Alagoas. Ela funciona durante os três turnos e oferta, exclusivamente, o Ensino Médio.

2 A monitoria proposta pela Secretaria de Educação do Estado de Alagoas é uma política para contratação de professores substitutos (entre estudantes com mais de 50\% da graduação e graduados nas diversas áreas de licenciaturas e afins). Estes são contratados por um período de um ano, prorrogáveis por igual interstício, e pretende suprir provisoriamente a carência de professores da Educação Básica, com prioridade para o Ensino Médio.

${ }^{3}$ Conforme Bakhtin (2003, p. 23), "O excedente de visão é o broto em que repousa a forma e de onde ela desabrocha como uma flor. Mas para que esse broto efetivamente desabroche na flor da forma concludente, urge que o excedente de minha visão complete o horizonte do outro contemplado sem perder a originalidade deste. [Para tanto, é preciso] colocar-me no lugar dele e, depois, de ter retornado (...), contemplar o horizonte dele com o excedente de visão que desse meu lugar se descortina fora dele, convertê-lo, criar para ele um ambiente (...) a partir do meu sentimento".
} 
se outro em relação a si mesmo, olhar para si mesmo com os olhos do outro" (BAKHTIN, 2003, p.13, grifo do autor). Mas isso não é um movimento operado facilmente, embora assim pareça quando descrito. Ao contrário, tal como adverte Bakhtin (2003),

É necessário algum esforço para me imaginar a mim mesmo nitidamente en face, desligar-me por completo de minha auto-sensação; conseguido isto, somos afetados em nossa imagem externa por algum vazio original e um estado de solidão um tanto terrível dessa imagem (Idem, p. 28).

Além disso, expor sua prática pedagógica na própria pesquisa é, de certo modo, verse/vendo nesse "excedente de visão" de muitos outros, especialmente quando se trata de dar testemunho desse cotidiano vivido em sala de aula. Nesse sentido,

Trata-se precisamente de me traduzir da linguagem interna para a linguagem da expressividade externa e entrelaçar-me inteiramente, sem reservas, com o tecido plástico único da vida enquanto homem entre outros homens, enquanto personagem entre outras personagens (Ibidem, p. 29).

Da posição de professor, é preciso "prestar conta" sobre o modo de ensinar e, sobretudo, sobre a indignação de lidar com os fracassos dos alunos que, apesar de estarem cursando o Ensino Médio, apresentam uma relação com a escrita com muitas dificuldades. Mas da posição de pesquisador, é um outro olhar - um outro modo de endereçamento. Não mais pela via de uma cobrança pedagógica, cuja preocupação limita-se muitas vezes em avaliar "erros" e "acertos" nas escritas dos alunos. Da posição de pesquisador foi possível colocar em potência a relação sujeitolinguagem que é forjada sob o estatuto da singularidade. Numa perspectiva bakhtiana, na qual se apoia a análise dos dados, os escritos desses alunos são assumidos como atos singulares enunciações, que emergem do universo de valores no qual o sujeito está socialmente situado. Retomando Bakhtin (2003, p. 2), quando falou sobre arte e vida, professor e pesquisador "não são a mesma coisa, mas devem tornar-se algo singular, em mim, na unidade da minha responsabilidade”. Mais ainda: do meu compromisso ético.

\section{NO CAMINHO DAS PEDRAS: O ROTEIRO METODOLÓGICO DA COLETA DE DADOS}

É importante salientar que a produção textual foi inspirada/motivada em temas/assuntos debatidos durante as aulas de Língua Portuguesa e, mais especificamente, da aula chamada de Redação (modelo ENEM) - na mesma disciplina. Antes de toda atividade de produção textual, liase textos previamente selecionados. Em seguida, conversava-se e argumentava-se sobre as mais 
variadas questões acerca da temática escolhida. Para iniciar a coleta das produções textuais foi preciso definir um roteiro prévio, que contemplou as seguintes etapas:

i. Aula sobre o gênero textual "redação de vestibular". Isso com o propósito de chamar a atenção para as características de tal gênero discursivo tanto do ponto de vista estrutural como da perspectiva funcional-social.

ii. Escolha do tema. A escolha do tema foi pautada na relevância para a faixa etária dos alunos. Ou seja, partiu-se do pressuposto de que tais textos fossem provocativos para fomentar o debate em sala de aula. Sendo assim, optou-se como primeiro tema - a importância da leitura. Para tanto, foi apresentado como "texto provocador" o artigo de opinião "A maior invenção da história”, de Arnaldo Niskier. O propósito da leitura era explorar a temática por meio do diálogo e do confronto de opiniões, levando os alunos a uma reflexão mais densa sobre o assunto proposto, além de forjar argumentos sobre o mesmo.

iii. O momento da produção textual. Foi solicitada uma atividade de escrita cuja consigna era Leitura: um poderoso instrumento libertário para o homem. Os alunos foram solicitados a realizar uma atividade discursiva: a produção de uma redação nos moldes dos exames de vestibular ${ }^{4}$, durante o tempo estimado de uma hora e trinta minutos (1h30), equivalente a dois tempos de aula. Enquanto essa atividade acontecia, o pesquisador fazia anotações no diário de bordo, procurando registrar, detalhadamente, a sequência didática desenvolvida durante a aula. Embora a aula seja planejada, somente a posteriori, no momento de sua execução, é que de fato ela ganha "voz(es)";

iv. Feedback. A quarta e última etapa consistia no feedback. Nesse momento, discute-se com os estudantes em quais pontos eles mais apresentaram dificuldades para que, professor e alunos, consigam juntos compreender as dificuldades apresentadas nos aspectos estruturais, sintáticos, lexicais, pragmáticos ou lógico-discursivos.

\footnotetext{
${ }^{4}$ Trata-se de um exame discursivo no qual cada estudante precisa escrever um texto dissertativo-argumentativo de até trinta linhas sobre um tema surpresa, geralmente que faz referência a alguma problemática nacional ou internacional relacionada à saúde, educação, segurança, política dentre outros assuntos. O padrão dissertativo-argumentativo exige que o aluno componha uma tese (posicionamento sobre o tema proposto) e faça a defesa desta no decorrer do seu texto. Para nortear o estudante, o próprio exame oferece como base alguns textos motivadores para que os alunos possam contextualizar o tema.

Enfim, o exame de vestibular é bastante comum no Brasil por ser a principal entrada de estudantes para as instituições de ensino superior mantidas pela União, Estados e/ou Municípios e Distrito Federal. O mais popular dentre todos, o Exame Nacional do Ensino Médio (ENEM), ocorre uma vez por ano, em dois dias consecutivos, entre os meses de outubro e dezembro.
} 
Esse percurso partiu do pressuposto de que para escrever, era preciso antes conhecer sobre o tema e sobre o gênero discursivo em pauta. Nesse sentido, o professor-pesquisador, compreendendo que outras leituras são fundamentais para exercícios de escrita, ajustou as atividades dentro desse padrão. Contudo, isso não significa dizer que só é possível escrever se tiver lido sobre determinado assunto, mas que conhecer o tema pode contribuir significativamente para o desenvolvimento do exercício.

Para concluir as quatro etapas descritas acima, foram dedicadas duas semanas de aula, ou seja, cerca de seis tempos de aulas: compreendendo desde as aulas sobre o gênero em questão, discussão acerca da temática, leitura e debate sobre o texto selecionado, a produção textual e o feedback.

\section{A LEITURA COMO PONTO DE PARTIDA PARA AS ESCRITAS}

Partindo da premissa de que toda comunicação humana ocorre por meio de textos (gêneros discursivos diversos) - independentemente da modalidade (escrita, oral ou mesmo imagética) - eles se tornaram a base para as aulas de redação. Além disso,

Os sujeitos, em situações reais de comunicação, se constituem no trabalho com os gêneros, ao mesmo tempo em que os gêneros se constituem no trabalho dos sujeitos. É uma 'via de mão dupla', um processo recíproco de constituição, e não um processo unilateral em que os gêneros estão constituídos e os sujeitos estão em constituição (VIDON, 2012, p. 421).

Em outras palavras, texto, autor e leitor estão implicados nesse processo sociointerativo no qual é forjada a linguagem humana. O ser humano se constitui na linguagem. Desse modo, é pertinente destacar que é através dos gêneros discursivos que o sujeito interage e se comunica com o mundo.

Embora, trate-se aqui da relação do aluno com as suas redações, não se pode desconsiderar que escrita e leitura, embora compreendidas como modalidades diferentes, estão desde sempre implicadas - tornando difícil pensar uma desvinculada da outra. Portanto, não se trata aqui de uma concepção de leitura como mera decodificação ou recepção passiva de um agrupamento de ideias. Ao contrário disso, ler é uma atividade dialógica com vistas à produção de sentidos. Enfim, o ato de ler exige uma tomada de posição:

A compreensão não é mera experienciação psicológica da ação dos outros, mas uma atividade dialógica que, diante de um texto, gera outro(s) texto(s). Compreender não é um ato passivo (um mero reconhecimento), mas uma réplica ativa, uma resposta, uma tomada de posição diante do texto (FARACO, 2009, p. 42). 
Tanto a leitura quanto a escrita são determinantes para que o sujeito conviva em sociedade. Ou seja, participando, ativamente, das diversas situações comunicativas. Segundo (FREIRE, 1989, p. 7), “Aprender a ler, a escrever é aprender a ler o mundo, não numa manipulação mecânica de palavras, mas numa relação dinâmica que vincula linguagem e realidade".

Enfim, elementos linguísticos, textuais/discursivos e contextuais são fundamentais para desenvolver as habilidades de leitura e de produção textual, pois nenhum texto é escrito fora de um tempo e de um espaço socioideológico. Ao invés disso, todo texto está inserido num contexto singular, situado num eixo temporal específico.

Também é fundamental compreender que o texto configura-se como a expressão de sujeitos. Não se pode nunca tomá-lo como um enunciado neutro - até porque a tentativa de neutralidade nada mais é, senão uma tomada de posição - visto que vem, pela própria questão estruturante da discursividade, eivado de ideologia. É relevante destacar que "A significação dos enunciados tem sempre uma dimensão avaliativa, expressa sempre um posicionamento social valorativo. Desse modo, qualquer enunciado é [...] sempre ideológico" (FARACO, 2009, p. 47, grifos do autor).

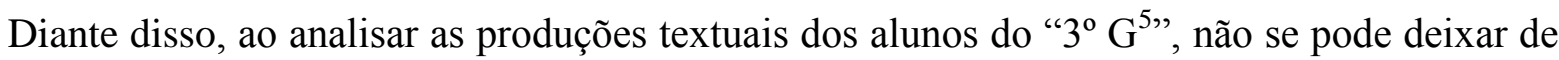
considerar que por trás do texto ecoa uma série de outros textos ${ }^{6}$, ademais ecoa uma visão de mundo, um universo de valores sociais, culturais e históricos - palavras alheias. Nessa perspectiva, juntos a esses ecos, também circulam as próprias vozes dos debates em sala de aula, tanto do professor como de outros alunos. É nessa ótica que lançaremos um olhar sobre as redações realizadas em sala de aula.

\section{O SINGULAR E O PLURAL: O ENTRELAÇAMENTO DE VOZES E O(S) NÓS NA TRAMA DA ESCRITA}

Esse recorte de dados tem o propósito de analisar os modos de inscrição do aluno na linguagem através de sua relação com a escrita. Para isso, considera-se o indivíduo um sujeito ideológico. Em outras palavras, cada sujeito possui uma visão de mundo singular, construída de acordo com as experiências vividas ao longo da vida. O que um indivíduo enxerga, lê e vive não é similar à vivência do outro. Na verdade, sua voz, seja na modalidade oral ou escrita, se inscreve a

\footnotetext{
${ }^{5}$ Turma selecionada para a pesquisa. Essa nomenclatura é adotada pela própria escola e corresponde a ordem alfabética. No caso "G" corresponde à sétima turma de $3^{\circ}$ ano do Ensino Médio.

${ }^{6}$ Princípio da intertextualidade. Segundo ele, a intertextualidade encontra-se na base de todo e qualquer dizer, ou seja, todo texto faz referência a outro(s) já produzido(s) e publicado(s) que é parte da memória social dos leitores, ainda que este não se dê conta disso no momento da escrita. Nesse sentido, existe uma série de textos que ecoam por trás das produções dos alunos do " $3{ }^{\circ} \mathrm{G}$ ".
} 
partir de determinado local - situado no tempo e no espaço. Uma voz que, embora singular, não é unívoca ou resultado exclusivo do pensamento do sujeito. O singular e o plural produzindo sentido à voz do sujeito.

Assim, se queremos estudar o dizer, temos sempre de nos remeter a uma ou outra esfera da atividade humana, porque não falamos no vazio, não produzimos enunciados fora das múltiplas e variadas esferas do agir humano. Nossos enunciados (orais ou escritos) têm, ao contrário, conteúdo temático, organização composicional e estilo próprios correlacionados às condições específicas e às finalidades de cada esfera da atividade (FARACO, 2009, p. 126, grifos meus).

Nenhum sujeito fala no vazio ou numa perspectiva total de neutralidade. Seu olhar é permanentemente moldado a partir de sua vivência com o mundo, das suas relações interpessoais e do contexto sócio-histórico em que o mesmo está inserido. Daí que o produto da escrita é resultado da interação do autor com o seu interlocutor, pois quando o primeiro escreve, o faz a partir de um outro. Por isso, tanto autor quanto leitor são atores sociais, sujeitos ativos que se constroem e são construídos durante a escrita, numa relação dialógica (BAKHTIN, 1999).

Nas palavras de Geraldi (2003, p. 102), “É porque se sabe do outro que um texto acabado não é fechado em si mesmo. Seu sentido, por maior precisão que lhe queira dar seu autor, e ele o sabe, é já na produção um sentido construído a dois". Desse modo, ao pensar em seu interlocutor, o autor procura afastar ao máximo as divergentes possibilidades de leituras que seu texto pode, de algum modo, evocar.

Quando se acreditava que o autor/falante/escritor era senhor absoluto da razão e, por isso, a realizava de modo completamente autônomo, houve uma simplificação do que seria o ato de escrever. Pensou-se que o ato de escrever era próprio da mente do indivíduo. Além disso, acreditouse também que, por conhecer o código linguístico, o sujeito já seria capaz de ter domínio sobre sua escrita e, consequentemente, ter uma compreensão linear de suas leituras. Entretanto, isso não acontece dessa maneira. "O discurso não pode controlar totalmente o discurso; todo texto leva consigo possibilidades de significação que escapam sempre de qualquer controle" (LARROSA, 1999, p. 117). Ou seja, os sentidos de um texto não são totalmente controláveis nem mesmo pelo seu próprio autor. Até mesmo porque os sentidos não estão no texto, mas surgem, a partir dele, em uma relação interativa que se dá entre autor/texto/leitor.

Desse modo, não se pode hipervalorizar o código linguístico em detrimento de todo o processo sociointerativo que ocorre na busca pelos sentidos. Portanto, o processo de produção textual não pode ser considerado apenas um produto da mente do autor, nem tão pouco pode se 
considerar que há garantias no processo de escrita pelo fato de se "dominar" o código linguístico no que se refere às suas questões normativas.

Ao compreender que não se fala no vazio, nem tomamos as palavras com significados engessados, mas, pelo contrário, valoramos as palavras conforme outros enunciados anteriores ao nosso, percebe-se que cada produção textual interage com um conjunto de vozes que circulam/circularam na sala de aula e, de modo geral, na escola e no mundo.

Antes de tratar dos ecos das variadas vozes que atravessaram as escritas dos alunos, faz-se fundamental destacar que o conceito de "voz" nesse trabalho não se restringe a emissão vocal de um falante, mas a qualquer forma de significação ou representação cultural sobre determinado assunto.

De maneira geral, a voz que mais ecoou na escrita dos alunos, sobre o tema Leitura: um poderoso instrumento libertário para o homem foi a que trata da leitura como um importante fator para o futuro profissional. Essa ideia configurou-se o "lugar mais comum" que as produções atravessaram, possivelmente por ser uma voz que reverberou significativamente no texto estudado, também na fala do professor-pesquisador, e nos debates em sala de aula. Além disso, é uma voz familiar e social a respeito da escola e dos estudos. Os fragmentos a seguir demonstram o quão marcado foi esse argumento:

Em nosso país muita gente passam por difíceis aperto, isto é por falta de estudo hoje são analfabetos. O homem hoje precisa ter muita leitura pra arrumar um emprego que dê para sustentar sua família, pois sem leitura e sem estudo não há emprego (E.R.). 


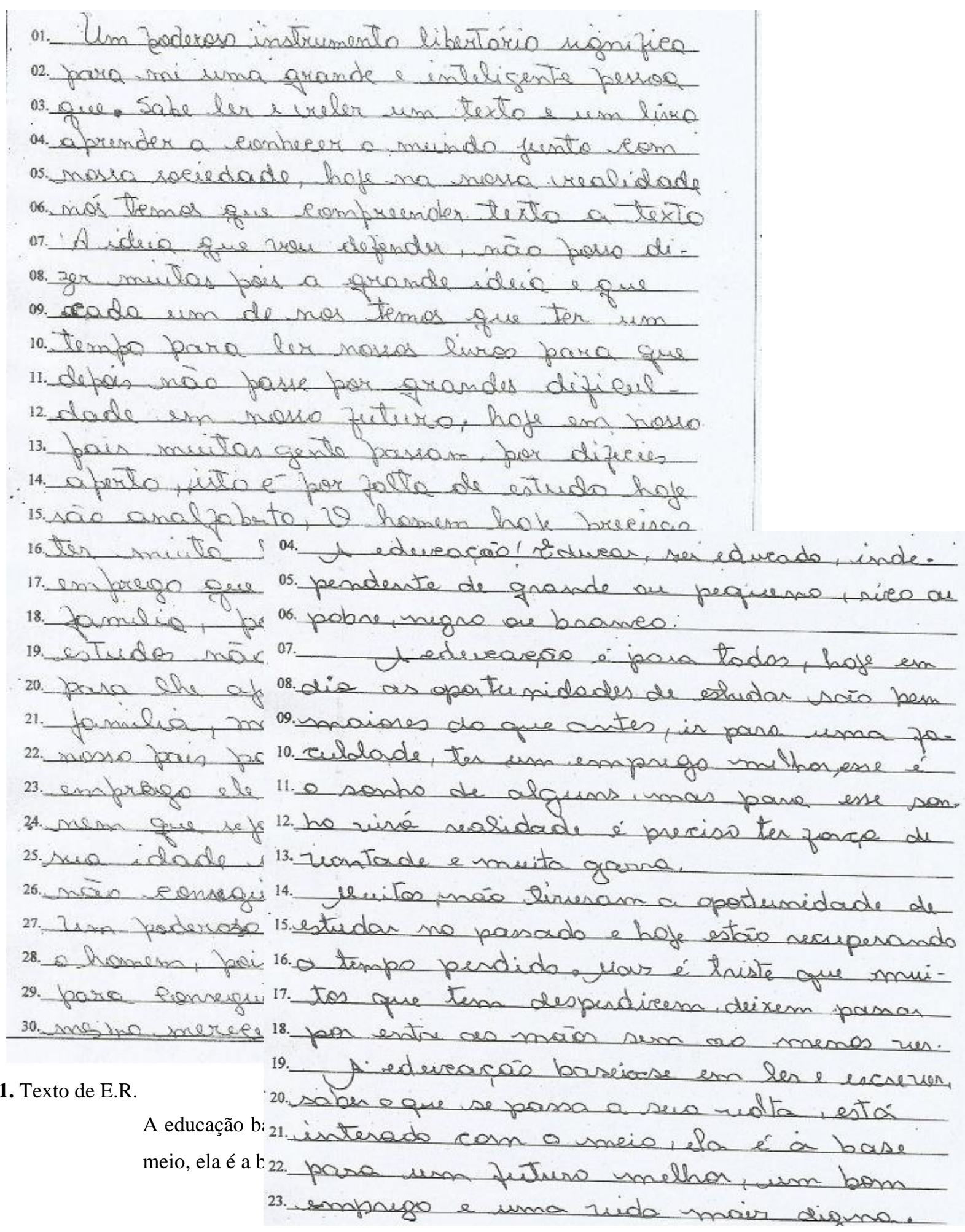

Figura 2. Texto do aluno V. L.

A partir desses recortes, é possível perceber que os alunos além de ressaltarem a leitura como algo importante para a formação, também elevam o papel da Educação. Ou seja, seus enunciados apontam para essa direção. Possivelmente atravessa-se aí a voz do professor que,

\footnotetext{
${ }^{7}$ Com o intuito de preservar a identidade de todos os sujeitos, respeitando os critérios éticos, seus nomes foram substituídos por iniciais de modo a compor uma sigla.
} 
durante as aulas, fez uma espécie de "pregação" sobre o valor da Educação tanto na escola como no convívio social. Além disso, também é possível que um amontoado de vozes sociais (da escola, do governo, da família, etc.) reforce esse sentido, considerando que existe um discurso culturalmente estabelecido que enaltece a Educação.

É nessa atmosfera heterogênea que o sujeito, mergulhado nas múltiplas relações e dimensões da interação socioideológica, vai-se constituindo discursivamente, assimilando vozes sociais e, ao mesmo tempo, suas inter-relações dialógicas. É nesse sentido que Bakhtin diz, figurativamente, que não tomamos nossas palavras do dicionário, mas dos lábios dos outros (FARACO, 2009, p. 84).

Em outras palavras, são dos dizeres já ouvidos/lidos que construímos o nosso dizer. É do já dito e vivenciado nas mais variadas interações humanas (sociais), que se constitui o sujeito. Existe uma relação de intertextualidade no nosso dizer, isto é, não tomamos as palavras do vazio, mas de outros dizeres que, de alguma forma, reforçam o nosso discurso. A palavra por si, isolada, não tem sentido nem autor algum.

A oração como unidade da língua, à semelhança da palavra, não tem autor. Ela é de ninguém,

[...] e só funcionando como um enunciado pleno ela se torna expressão da posição do falante individual em uma situação concreta de comunicação discursiva (BAKHTIN, 2006, p. 289).

Por fim, há ainda uma voz social que sugere a Educação como meio para o sucesso além do escolar, o sucesso profissional. Se, por um lado, sob o endereçamento deste liame social, os alunos tentam atender a expectativa do professor para quem eles precisam apresentar seus escritos; por outro, é interessante perceber que o estudante não se baseia apenas no texto motivador ou nos debates e leituras realizadas em sala de aula. Eles também constroem seu texto com base em diversos conhecimentos extrassala: seus conhecimentos de mundo. Trata-se de conhecimentos alusivos a experiências pessoais do indivíduo, a vivências nos mais variados contextos sociais a exemplo da família, do convívio com os amigos, na igreja, no futebol, na balada, ou mesmo na própria relação com as mídias, como a televisão, as diversas redes sociais, etc. O fragmento a seguir, pode explicar melhor o que estamos tentando dizer:

Hoje em dia saber ler é fundamental porque para ter a carta de motorista, fazer uma simples atividade do dia a dia como pegar um ônibus, andar de metro, ler uma placa na rua, comprar um remédio, etc. coisas simples por isso devemos mudar, vamos da uma basta para o analfabetismo no nosso pais mais em todo mundo, por que todos nós temos o direito de aprender a ler para ter uma vida boa na sociedade (J.F., grifos meus). 


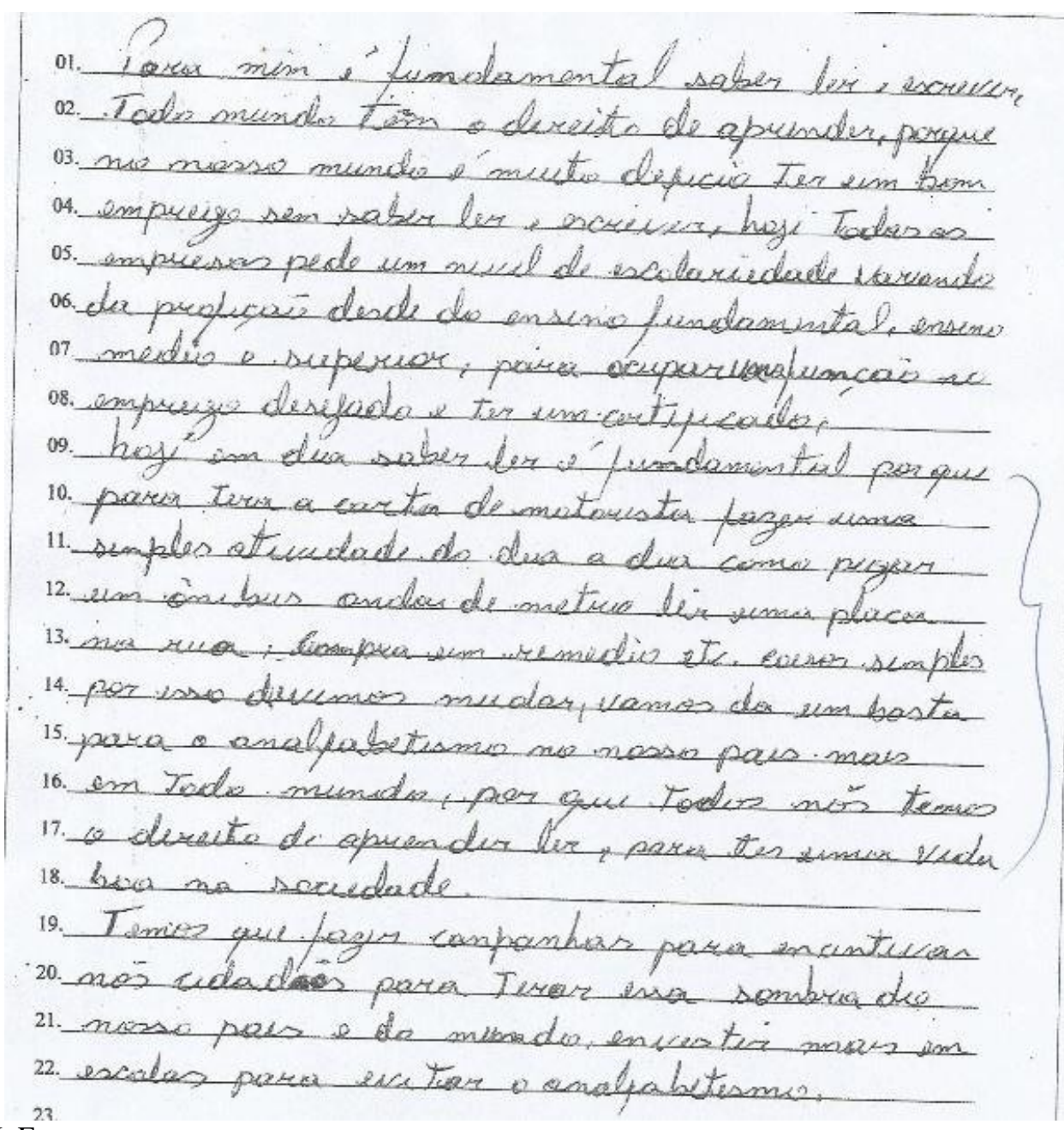

Figura 3. Texto de J. F.

É interessante como o aluno J.F. faz associações entre a leitura e atividades cotidianas, contudo é possível perceber que quando o mesmo faz referência a "andar de metrô", é algo mais singular. Afinal, o metrô não é parte da realidade do município de Boca da Mata, nem ainda do estado de Alagoas. Nesse sentido, de onde vem essa enunciação? Por que o mesmo não utilizou como exemplo um táxi ou mesmo um ônibus? Possivelmente, uma experiência pessoal dele atravessou sua escrita, seja pelo fato de ele já ter utilizado esse tipo de transporte, por ter ouvido algum familiar ou amigo falar a respeito ou por ter visto, ainda que pela televisão ou internet, como funciona uma estação de metrô.

Além disso, quando o estudante diz que ler é fundamental para obter a carteira de motorista revela outra vez uma voz que vai além das vozes dos textos motivadores, do professor e dos debates em sala de aula. É, possivelmente, mais uma voz que ecoa de experiências externas à escola. Enfim, não se pode negar o fato de que o aluno traz consigo uma série de conhecimentos de mundo que são ativados durante as atividades de produção textual. 


\section{REBUSCAMENTO: O DESEJO DE "FALAR DIFÍCIL"}

É possível identificar o efeito do uso de vocabulário rebuscado quando alguns alunos, impregnados de outras vozes e do desejo de "falar difícil" (tal como a escola recomenda, entendendo que isso se configura como norma culta), estão marcados por essas palavras. Sobre isso, é importante destacar:

O emprego das palavras na comunicação discursiva sempre é de índole individual contextual. Por isso, pode-se dizer que qualquer palavra existe para o falante em três aspectos: como palavra da língua neutra e não pertencente a ninguém; como palavra alheia dos outros, cheia de ecos de outros enunciados; e, por último, como a minha palavra, porque uma vez que eu opero com ela em uma situação determinada, ela já está compenetrada na minha expressão (BAKHTIN, 2006, p. 294).

Nesse sentido, compreende-se que as palavras quando escolhidas seja para uma fala ou para um texto que fala, não ocorre de modo aleatório. No percurso inverso, a escrita é afetada por outros escritos, por palavras alheias dos outros até configurar-se como palavra do autor. Diante disso, ao identificar como as palavras alheias afetam os textos dos alunos, percebe-se que o rebuscamento é um dos aspectos marcantes. Ele ocorre pelo uso de termos dos mais variados; alguns, inclusive, afetam a semântica do texto e dificultam a compreensão para os possíveis interlocutores.

Para demonstrar tal situação, é interessante observar os excertos a seguir:

Pra mim eu acho que o homem tem o poder liberal Para se capacita para ter um bom desempenho de ser uma pessoa educativa.

Como Porque ser um instrumento de Ser um indivíduo para ter as Habilidade exigida Pelos instrumentos cardeais (G.P. - Grifos meus). 


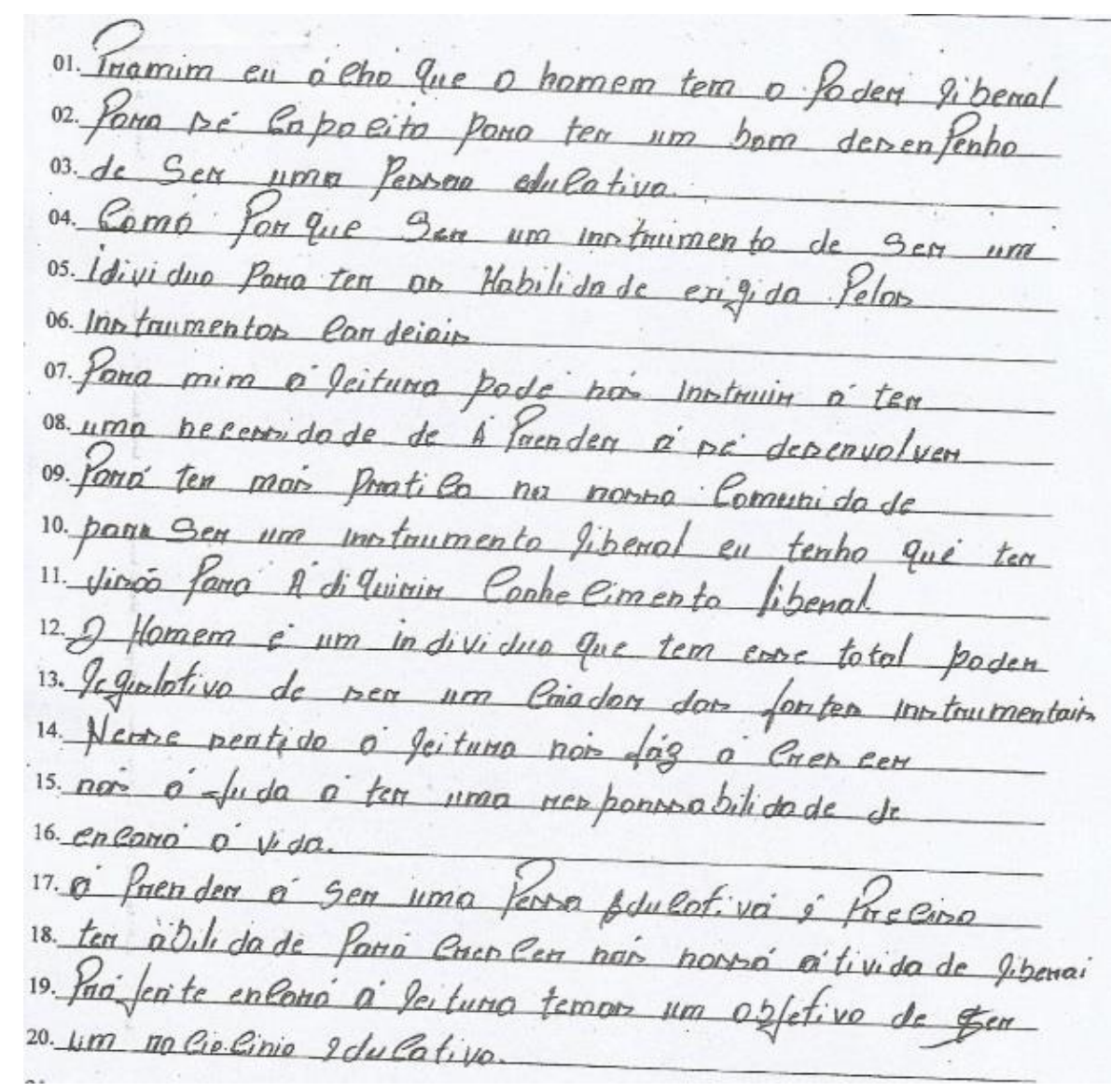

Figura 4. Texto de G.P.

Embora o excerto apresente diversos problemas de ordem morfossintática, não pretendo deter-me nesses aspectos. Ao invés disso, é pertinente salientar a estética do texto de G.P. Nele se revela uma espécie de deslizamento que, possivelmente, são efeitos de "palavras alheias" (BAKHTIN, 2003) e/ou de termos que lhe soam rebuscados, o que termina provocando a escrita de expressões nonsense. Ou seja,

As palavras no processo de construção de um enunciado, nem de longe as tomamos sempre do sistema da língua em sua forma neutra, lexicográfica. Costumamos tirá-las de outros enunciados, e antes de tudo de enunciados congêneres com o nosso (BAKHTIN, 2006, p. 292).

Ao ler o texto de G.P, as expressões "poder liberal” e "instrumentos cardeais" chamam atenção de modo particular. É possível que a presença dos termos "instrumento" e "liberdade", que por repetidas vezes ocorrera tanto no texto de Niskier - a exemplo do fragmento "A leitura se configura como um poderoso e essencial instrumento libertário para a sobrevivência humana" (Niskier), bem como nos excertos motivadores em sala de aula, tenham endereçado o aluno a esse caminho. Além disso, a própria proposta da redação também já (de)marcava um cruzamento com as palavras que circulavam no texto do membro da Academia Brasileira de Letras (ABL): Leitura um poderoso instrumento libertário para o homem. Já o termo cardeal, combinado ao termo instrumento, não é possível ter garantias sobre os ecos de vozes que nele ressoam. Contudo, 
Na relação criadora com a língua não existem palavras sem voz, palavras de ninguém. Em cada palavra, há vozes às vezes infinitamente distantes, anônimas, quase impessoais [...], quase imperceptíveis, e vozes próximas que soam concomitantemente (BAKHTIN, 2006, p. 330).

É ainda pertinente destar ${ }_{02}^{01}$ ele sesa dar tiberta a liberdade pora que ;uagem demonstra-se rebuscada, de al vocabulário menos comum. É p escolha didática do pesquisado panfletário e moralizante, o quє alunos de assumirem vocabuláric

Outra marca de rebusci conteúdo semântico, aparece no

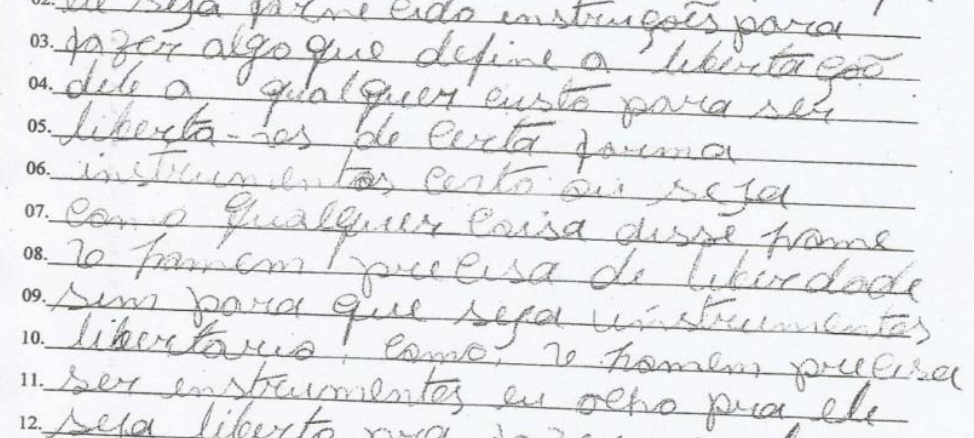
12. seja liberto wura to zer arowetes zar um zvido à caráter ras dos de seu 14. a posse a passo, nas sefa posiand.

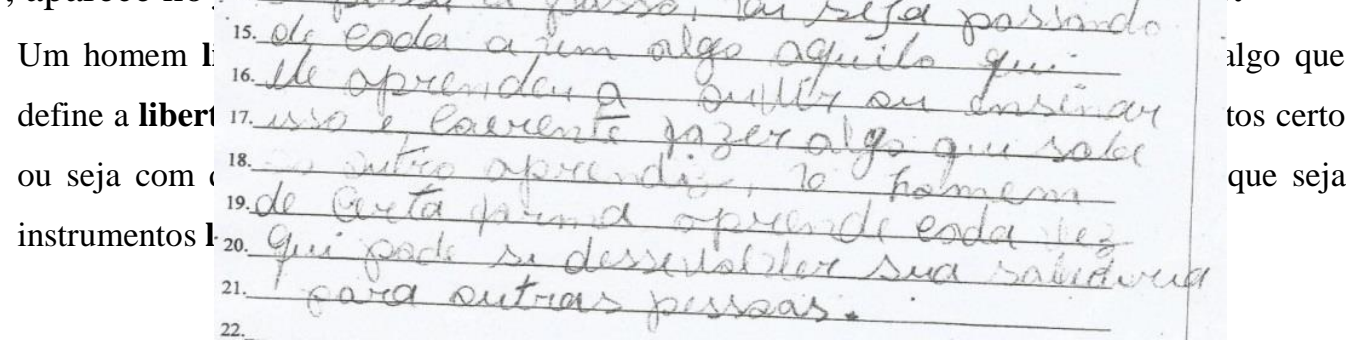
Figura 5. Texto de M.S.

Ao analisar o texto acima, nota-se, especialmente no primeiro período, aspectos de organização sintático-semântica. É possível que isso ocorra porque a aluna se fez afetada por palavras menos usuais. É curioso observar o atravessamento do discurso escolar, fazendo pregnância nas escritas dos alunos, (de)marcando seu lugar de aluna e ao mesmo tempo sua posição - enquanto sujeito singular. "O que existe é um jogo tenso, um mútuo descentramento às vezes violento, um diálogo apaixonado em que cada um dos polos tira o outro de suas posições e, às vezes se deixa inquietar por ele" (LARROSA, 1999, p. 121).

Não é por outra razão, que o último período destacado da escrita de M.S traz uma carga semântica bastante pertinente: "O homem precisa de liberdade sim para que seja instrumento libertário" (M.S. Grifo meu). O termo sim, confirmando seu lugar afirmativo, não deixa de ecoar apelativo - cujo tom parece, do ponto de vista sintático, bastante enfático.

\section{TÓPICOS DE REDAÇÃO E O ATRAVESSAMENTO DE OUTROS GÊNEROS: A DIVISÃO DO SUJEITOO}

Embora se entenda o texto como uma unidade única capaz de, na interação entre autorleitor, possibilitar a (re)construção de sentidos, esse todo, muitas vezes, aparece fragmentado na produção dos alunos. Entre as diversas situações em que é possível observar essa quebra de 
unidade, pode-se citar justamente àquelas em que o aluno delimita por um entretítulo ${ }^{8}$, porquanto deixa a fragmentação mais evidente, como no excerto abaixo:

Conclusão

Eu acho que hoje em dia a maioria dos adolescentes não querem saber de estuda, só estão querendo saber de curtições. [...]

mas na minha opinião se todos nos, nos interessasse mas nos estudos, seria muito importante para o pais [...].

Moral do texto: o estudo esta acima de tudo (W. A.)

\footnotetext{
${ }^{8}$ É possível perceber a quebra da unidade mesmo quando o autor não apresenta um entretítulo, na maioria das vezes quando o aluno perde o seu norte na escrita, atravessando por outros temas ou circunstâncias que não a exigida na atividade, contudo trataremos aqui apenas os que apresentam a marca estrutural dos subtítulos/entretítulos.
} 


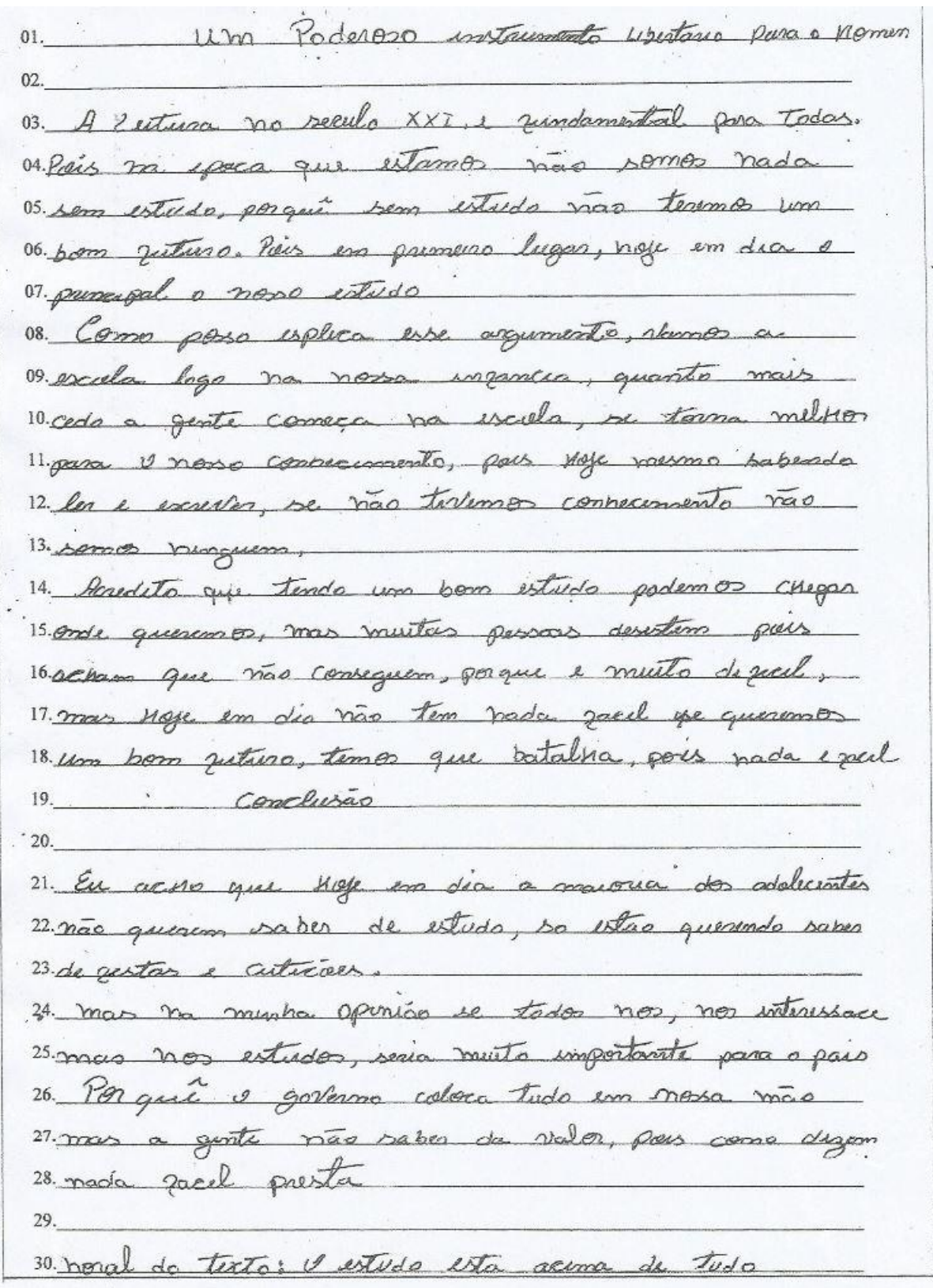

Figura 6. Texto de W.A.

O aluno deixa marcada sua entrada no que seria a conclusão do texto. Possivelmente isso ocorreu devido à ênfase dada nas partes que compõem uma redação de vestibular: introdução, desenvolvimento e conclusão, durante as primeiras aulas sobre o assunto ou durante alguma das revisões. Faz-se necessário salientar que em nenhum dos textos lidos em sala de aula, tanto desse gênero como de outros diversos, apresentava a conclusão após entretítulo. Exatamente no sentido oposto, os textos sempre apareciam sem nenhum subtítulo ou entretítulo.

Ao tratar das aulas sobre aspectos estruturais, enquanto professor de Língua Portuguesa, costumava subdividir as partes que compõem uma redação e tratar dos objetivos específicos de cada uma delas, de modo a se completarem/complementarem formando a unidade textual. Em outras 
palavras, a introdução funciona para apresentar uma tese, um ponto de vista sobre o tema; o desenvolvimento para expor argumentos no sentido de desenvolver um raciocínio que esclareça ao leitor as razões pelas quais se evidencia a tese; e, por último, a conclusão serve para apresentar uma proposta de intervenção ligada à situação-problema do tema e dar um fechamento ao texto. Talvez, esta tentativa, em minha aula, de tornar a explicação mais didática - separando as partes da redação para estudá-las, a princípio, isoladamente e, só depois, torná-las como um todo - tenha sido tão evidenciada que acabou direcionando alguns alunos a fragmentarem sua produção em algumas partes. Possivelmente, eles tenham reproduzido isso para as suas redações acreditando, de alguma forma, que isso poderia servir de controle à sua escrita - uma espécie de contenção às suas palavras. Ou seja, procurar não escapar daquilo que fora ditado pelo professor - uma espécie de "garantia" para escrever um texto dissertativo-argumentativo.

Nesse sentido, é pertinente retomar Bakhtin (2006, p. 294), quando afirma: "a experiência discursiva individual de qualquer pessoa se forma e se desenvolve com uma interação constante e contínua com os enunciados individuais dos outros”. Em outras palavras a voz do professor em sala de aula, que destacou as subdivisões do gênero redação, ressonou na escrita dos alunos, que, para atenderem a proposta do docente, assimilaram as palavras do outro. Assim, percebe-se a disposição do aluno em seguir a orientação do professor. É curioso observar que, ao escrever, não tomamos as palavras diretamente da língua, mas as tomamos de outros enunciados, na maioria dos casos congêneres com o nosso.

Outro dado interessante, presente nesse excerto/texto, é que outro gênero textual atravessa a escrita de W.A: a fábula. Nenhum outro estudante deixou escrito uma moral da história. Embora ele tente seguir o mote do gênero redação de vestibular, inclusive destacando a conclusão, o mesmo subverte-o com o atravessamento de característica de outro gênero. No entanto, a moral da história numa fábula, por exemplo, trata-se exatamente de um fechamento do texto, uma conclusão.

Nesse atravessamento, inclusive de ordem estilística, há indícios do tom moralizante que se forja, quase sempre, na palavra do professor numa relação de ensino. Além disso, a própria temática da redação, A leitura como instrumento libertário para o homem, enredou W.A em uma moral. A ideia da moral não parece ter ocorrido por algum diálogo entre alunos-professor-texto-classe - pelo menos não nas aulas do $3^{\circ} \mathrm{G}$-, diferente disso, aparenta ser algo singular, pessoal, no qual o estudante "percebeu" uma necessidade desse complemento, desse arranjo final. Talvez por alguma aula de anos letivos anteriores ou ainda por uma identificação própria do mesmo com textos que deixam algum tipo de ensinamento, de lição. Nas palavras de Larrosa (1999, p. 145) "a lição dá a liberdade de tomar a palavra". Ou seja, apesar de querer adequar-se a proposta de escrita sugerida 
pelo professor, ao mesmo tempo, ele subverte e toma para si a palavra, aproveitando a liberdade da lição.

\section{CONSIDERAÇÕES FINAIS}

São de comum acordo que tanto o texto como a produção textual devem estar presentes nas salas de aula, uma vez que são essenciais para o estudo das mais variadas disciplinas. Nesse sentido, o professor deve, sempre que possível e/ou necessário, “dar a ler”. Nas palavras de Geraldi (2003, p. 188) "a entrada de um texto para a leitura em sala de aula responde a necessidades e provocam necessidades". O texto é gerador de espaços para discussões, proporcionando a ocasião para o dizer; é o espaço para interlocução; é ainda, ao mesmo tempo, o lugar onde o autor registra seu enunciado/voz na modalidade escrita. Contudo, esta voz não é unívoca, mas configura-se uma ressonância de outras leituras e de outras vozes.

De modo semelhante, percebe-se que a produção escrita dos alunos, no gênero redação de vestibular, também denominado como texto dissertativo-argumentativo, está quase sempre (se não sempre) atravessada pela voz do professor, pela sua aula e também por suas escolhas didáticas. Foi possível perceber que cada escolha realizada pelo professor, num maior ou menor grau, interfere diretamente no resultado da produção textual dos alunos. Nesse sentido, o professor apresenta-se como uma personagem presente no texto do aluno, numa relação semelhante à de coautoria, pois os estudantes escrevem, quase sempre, pensando em agradá-lo, ou seja, sendo afetados pela palavra do educador. Assim, a figura do professor se configura como "o outro", a quem o texto se dirige e, sem o qual, o texto sequer existiria. Isso porque o principal interlocutor da produção escrita do aluno é justamente o docente. Desse modo, o professor se inscreve no texto do estudante não apenas quando o lê, mas inscreve-se ainda quando o texto está em fase de construção.

Por outro lado, os alunos, por já terem um conhecimento prévio tanto da língua como do mundo à sua volta também têm a liberdade de "tomar a palavra". Ao mesmo tempo em que tentam seguir orientações do educador, tomam a palavra e se expõem no texto, muitas vezes, inclusive, transgredindo o gênero em tela. Não se pode perder de vista que toda leitura, assim como toda escrita, é, na verdade, um processo dialógico, no qual leitor e autor interagem no interior do texto com o intuito de produzir sentidos.

Apesar de o autor utilizar uma série de estratégias para que seu interlocutor o compreenda, percebe-se que é impossível controlar os sentidos do texto, seja este oral ou escrito. Não há nenhuma garantia de que a escuta que o aluno faz do professor ou do texto escolhido por este seja, 
de fato, a pretendida pelo autor da enunciação. No sentido oposto, é justamente pela e na relação dialógica do ouvinte/leitor com a fala/texto que os sentidos se materializam de modo singular. Portanto, os sentidos não estão simplesmente dentro do texto, como se este fosse uma espécie de caixa, de refratário onde se põe palavras com sentidos predeterminados e rigidamente fixados, mas surgem a partir da relação que o interlocutor estabelece com o texto durante o processo de leitura. Essa questão revela-se inclusive no próprio ensino, considerando que não há caminhos que garantam o aprender, mas o ensino-aprendizagem ocorre no dialogismo da própria sala de aula, na interação verbal entre professor-aluno que constantemente deslocam-se um na direção do outro numa tentativa de se fazerem entender por meio de (suas) palavras. E nisto se faz a pre-tensão do ensino que, mais do que estabilidade no/do saber, provoca outras (indis)posições nos sujeitos implicados neste ato.

Enfim, professor-pesquisador e aluno estão num constante deslocamento durante o processo de ensino-aprendizagem, alvos de armadilhas da língua. A sala de aula é o espaço do dizer, onde ecoam vozes sociais das mais diversas que dialogam com as (outras) vozes do professor e dos estudantes. Vozes perturbadoras das ordens prescritas e provocadoras de muitas indisposições. E, certamente por esta razão, para Bakthin (2003) a linguagem escrita tem outra função grandiosa: a de transgredir a norma, o poder institucionalizado pela gramática, e tem como função maior a expressividade. Assim, a entrada do texto em sala de aula, ainda durante a leitura, permite a participação de um autor, que também não é sozinho a origem da escritura, mas em conjunto com uma série de outras escritas. Desse modo, o texto apresenta-se com um lugar de entrada para um diálogo com outras vozes. Compreende-se, assim, a importância da produção textual em sala de aula. Considerando que a escrita - dando realce ao sujeito de linguagem - revela o aluno como um sujeito dialógico afetado por tantas palavras e textos.

\section{REFERÊNCIAS}

BAKHTIN, Mikhail. Estética da criação verbal. São Paulo: Martins Fontes, 2003.

. Gêneros do discurso. In: Estética da criação verbal: introdução e tradução do russo Paulo Bezerra; prefácio à edição francesa Tzvetan Todorov. 4. ed. São Paulo: Martins Fontes, 2006.

. Marxismo e filosofia da linguagem. São Paulo: Hucitec, 1999.

BRASIL. A redação no ENEM 2013: guia do participante. Brasília-DF: INEP/MEC, 2013.

FARACO, Carlos Alberto. Linguagem \& Diálogo: as ideias linguísticas do círculo de Bakhtin. São Paulo: Parábola Editorial, 2009.

FREIRE, Paulo. A importância do ato de ler em três artigos que se completam. 23 ed. Coleção Polêmicas do nosso tempo. São Paulo: Autores Associados: Cortez, 1989.

GERALDI, João Wanderley. Portos de passagem. 4 ed. São Paulo: Martins Fontes, 2003. 
LARROSA, Jorge. Pedagogia profana: danças, piruetas e mascaradas. Belo Horizonte: Editora Autêntica, 1999.

VIDON, Luciano Novaes. Autoria em redações de vestibular: considerações a partir da perspectiva bakhtiniana. Revista Estudos Linguísticos, São Paulo: 2012.

Submetido em 05 de fevereiro de 2017

\section{RESUMO}

Este trabalho objetiva analisar, do ponto de vista linguístico, a produção textual de alunos do $3^{\circ}$ ano do Ensino Médio de uma rede pública de ensino, situada no Estado de Alagoas. Tal produção textual diz respeito a uma redação de vestibular - modelo ENEM. Vale ainda dizer que esse artigo é um recorte de uma dissertação de mestrado, cujo foco foi tentar compreender como as mais variadas vozes que ecoam em sala de aula estão atravessadas de algum modo no texto dos alunos. Para tanto, filiamo-nos teoricamente à perspectiva bakhtiniana (2006; 2003), colocando em destaque também estudiosos como Geraldi (2003), Larrosa (1999) e Faraco (2009).

Palavras-chave: Produção textual. Vozes. Redação de vestibular.

\section{WORDS DO NOT BELONG TO ANYONE: THE MULTIPLE VOICES THAT ECHO IN TEXTUAL PRODUCTION IN CLASSROOM}

\section{ABSTRACT}

This paper aims to analyze, from the linguistic view, the textual production of students of the 3rd year of High School in the public school system, in th e State of Alagoas. The textual production concerns the writing essay - ENEM model. It is worth pointing out this study is the result of a mater's research whose focus was to try to understand how the most varied voices that echo in the classroom are crossed, in some way, in the text of the students. To do it, we use the Bakhtinian perspective $(2006 ; 2003)$ highlighting also scholars such as Geraldi (2003), Larrosa (1999) and Faracco (2009).

Keywords: Textual production. Voices. Essay writing. 